\title{
Comparative analysis of the performance of two different platforms for femtosecond laser-assisted cataract surgery
}

This article was published in the following Dove Press journal:

Clinical Ophthalmology

19 October 2016

Number of times this article has been viewed

\author{
Robert P Rivera ${ }^{\dagger}$ \\ Phillip C Hoopes Jr \\ Steven H Linn \\ Phillip C Hoopes \\ Hoopes Vision, Draper, UT, USA \\ ${ }^{\dagger}$ Dr Rivera passed away on \\ April I, 2015
}

Correspondence: Phillip C Hoopes Jr Hoopes Vision, Draper, UT 84020, USA Tel +I 80I 5680200

Email pchj@hoopesvision.com
Purpose: To analyze and compare the intraoperative and postoperative outcomes of cataract surgery performed with two different femtosecond laser platforms.

Methods: Randomized controlled prospective intraindividual comparative study including 90 eyes of 45 patients aged between 61 and 86 years. All eyes underwent bilateral cataract surgery assisted with femtosecond laser technology. Eyes were randomized to one of two different femtosecond laser platforms: Catalys Precision system (Abbott Medical Optics Inc., Santa Ana, CA, USA) (Catalys group), and LenSx system (Alcon-LenSx Inc., Aliso Viejo, CA, USA) (LenSx group). Several intraoperative parameters and changes in corrected distance visual acuity and corneal endothelial density were evaluated and compared.

Results: The LenSx group showed a significantly higher cumulative dissipated energy and phacoemulsification power needed compared to the Catalys group $(P \leq 0.043)$. Likewise, a longer patient interface preparation time, more severe perception of pressure by patient, and more cases of subconjunctival hemorrhage were found in the LenSx group $(P \leq 0.014)$. A complete capsulotomy was achieved in more cases in the Catalys group compared to the LenSx group $(P=0.002)$. Regarding corneal incisions, no statistically significant differences were found between groups $(P \geq 0.071)$. The same occurred for postoperative corrected distance visual acuity ( $P \geq 0.48$ ), endothelial cell density changes $(P \geq 0.14)$, and the incidence of corneal edema or flare $(P \geq 0.399)$.

Conclusion: Cataract surgery with the two evaluated femtosecond laser platforms is a safe procedure, with reduced phaco time and energy, and preservation of corneal endothelium integrity. However, both systems differ in the performance of capsulotomy and the procedure of docking, with an advantage of the Catalys over the LenSx system.

Keywords: femtosecond laser-assisted cataract surgery, capsulotomy, docking, hemorrhage

\section{Introduction}

As cataract patients are now more demanding and search for spectacle independence, the aim of cataract surgery has currently evolved to the achievement of a complete and fast visual rehabilitation, with minimal postoperative residual refractive error. The improvements in the control of the corneal incision, ${ }^{1}$ the development of new intraocular lens (IOL) models of increased quality, ${ }^{2}$ and the development of new tools facilitating the surgical procedure are factors that have contributed significantly to the optimization of the outcomes after cataract surgery. In this context, one of the most relevant advances is the development of femtosecond laser systems to perform anterior capsulotomy, lens segmentation, and corneal incisions during cataract surgery. ${ }^{3-5}$ This new technology provides several advantages to the surgeon over the conventional 
technique, such as the performance of very precise circular and adjustable diameter capsulotomies, ${ }^{6-9}$ precise lens nucleus fragmentation, ${ }^{9}$ the creation of multi-planar selfsealing incisions with better wound architecture, ${ }^{10}$ exact placement of limbal relaxing incisions, ${ }^{10}$ and the reduction of phacoemulsification time..$^{8,11-13}$ Various systems based on this femtosecond laser technology have been commercially released in the last few years. ${ }^{14}$

Good clinical outcomes have been reported with femtosecond laser-assisted cataract surgery. Specifically, this technology has been shown to be superior in terms of effective phaco time, ${ }^{8,11-13,15}$ corneal endothelium damage ${ }^{16}$ and some other clinical parameters over conventional manual phacoemulsification. ${ }^{12,15,16}$ Likewise, some evidences of the significant benefit of using the femtosecond laser technology for cataract surgery in complex cases have been also reported. ${ }^{17-20}$ However, to date, no studies have been performed aimed at comparing the outcomes with different femtosecond laser platforms for cataract surgery in order to detect and characterize potential clinically relevant differences. The aim of the current study was to analyze and compare the intraoperative and postoperative outcomes of cataract surgery performed using two different femtosecond laser platforms that are currently commercially available.

\section{Methods}

\section{Patients}

In this randomized controlled prospective intraindividual comparative study, a total of 90 consecutive eyes of 45 patients with ages ranging between 61 and 86 years were included. All eyes were scheduled for cataract surgery due to the presence of visually significant senile cataract (corrected distance visual acuity [CDVA] $<0.2$ LogMAR). The exclusion criteria were history of glaucoma or retinal detachment, corneal disease, irregular corneal astigmatism, abnormal iris, macular degeneration or retinopathy, neuro-ophthalmic disease or history of ocular inflammation. The patients were divided into two groups according to the femtosecond laser platform used. Only patients with equal cataract grades were enrolled. In this intraindividual comparison, the worse eye, as defined by visual acuity, underwent surgery first and was randomized to treatment with one of the laser platforms. The fellow eye underwent surgery with the other laser platform: 45 eyes undergoing cataract surgery with the Catalys Precision system (Abbott Medical Optics Inc, Santa Ana, CA, USA) (Catalys group), and 45 eyes with the LenSx system (Alcon-LenSx Inc, Aliso Viejo, CA, USA) (LenSx group). All surgeries were performed between April 2013 and January 2014.
All subjects were adequately informed and signed a consent form. The study adhered to the tenets of the Declaration of Helsinki and was approved by Salus Institutional Review Board.

\section{Examination protocol}

Preoperatively, all patients underwent full ophthalmologic examination, including the evaluation of the refractive status, LogMAR CDVA testing, slit lamp examination, Goldmann applanation tonometry, biometry (IOL-Master v.3.01, Carl Zeiss Meditec, Dublin, CA, USA), corneal endothelial count (EM 3000, Tomey Corp, Nagoya, Japan), and fundoscopy. The lens opacities were graded by the surgeon (PCH Jr or RPR) from 1 (very low) to 4 (very high) according to the Lens Opacity Classification System III. For such purpose, a BQ 900 slitlamp (Haag-Streit, Mason, OH, USA) was used at maximum illumination without light filtering. Postoperatively, patients were evaluated during the follow-up at 1 day, 1 week, and 1 month after surgery. At 1 day after surgery, uncorrected distance visual acuity, intraocular pressure (IOP), and the integrity of the anterior segment were evaluated. The postoperative examination protocols at 1 week and 1 month were identical to the preoperative protocol.

\section{Surgery}

All surgeries were performed by one of two experienced surgeons (PCH Jr and RPR) using a standard $2.9 \mathrm{~mm}$ sutureless microcoaxial phacoemulsification technique. The femtosecond laser treatment was applied before ultrasound phacoemulsification and IOL implantation. All patients were placed in a stretcher (Steris Hausted Surgi-Stretcher; LenSx) or fixed reclined built-in bed (Catalys) and positioned supine beneath the system, and each eye received topical tetracaine (tetracaine hydrochloride ophthalmic solution, United States Pharmacopeia, 0.5\%, Bausch + Lomb) eyedrops to establish anesthesia.

With the Catalys system, the two-piece Liquid Optics Interface $\left(\mathrm{LOI}^{\mathrm{TM}}\right)$, which consists of a suction ring and a nonapplanating immersion lens, was positioned on the limbus and suction applied. Once suction and fixation of the globe were confirmed, the fluid reservoir was filled with balanced salt solution, and the patient was brought under the laser lens and docked to the system. The dimensions of the anterior chamber and the crystalline lens were then measured by using a three-dimensional (3D) spectral-domain optical coherence tomography (OCT) system, which is incorporated in this laser platform. The results were presented to the surgeon for confirmation of the system's automatic detection and placement of treatment zones, and for adjustment and/or 
redesign of the $5.0 \mathrm{~mm}$ capsulotomy and tissue interfaces as needed. Once the surgeon verified all relevant parameters, the selected treatment was initiated.

With the LenSx system, a lid speculum was placed and the laser was docked to the eye using a curved contact lens (SoftFit) to applanate the cornea. As with the Catalys system, the location of the cornea, and the anterior and posterior surfaces of the crystalline lens was determined with the integrated OCT imaging system. A $5.0 \mathrm{~mm}$ diameter capsulotomy was created by scanning a cylindrical pattern, and the lens was fragmented into quadrants and cylinders. After laser pretreatment of the crystalline lens, corneal incisions were created in both groups also using the femtosecond laser platform. Furthermore, limbal relaxing incisions were programmed in those cases with significant amounts of corneal astigmatism.

Two settings for nuclear treatment were selected on each laser platform to correspond with the degree of lens density. On the Catalys, nuclear sclerotic lens grades of 2-3 were treated with a quadrantization pattern and a $500 \times 500 \mu$ segmentation pattern; higher lens grades were treated with quadrantization and a $350 \times 350 \mu$ segmentation. On the LenSx, grades $2-3$ were treated with a quadrantization combined with a single cylinder; higher lens grades were treated with creation of sextants and eight concentric cylinders.

Each laser procedure was followed by ultrasound phacoemulsification using the same phacoemulsification machine (Infinity, Alcon). The IOL was then inserted into the capsular bag using the corresponding specific injector for each IOL. The same postoperative treatment was administered to all patients consisting of corticosteroid-antibiotic combination eye drops. Intraoperatively, the following parameters and variables were recorded: patient interface preparation time (time to unpack, assemble, and dock), number of attempts of docking, suction time (suction ON to suction OFF), perception of pressure by patient ( 0 -none, 5 -severe), loss of vision (yes or no), ease of opening of corneal incisions evaluated by surgeon (open, difficult, or closed), complete capsulotomy (yes or no), self-sealing corneal incisions (yes or no), number of $5 \mathrm{cc}$ syringes used to seal incisions, nucleus removal time, cortical removal time, cumulative dissipated energy (CDE), number of capsule tears, incidence of subconjunctival hemorrhages, effective phacoemulsification time (EPT), total ultrasound power, average phacoemulsification power, average torsional amplitude, amount of fluid used, and aspiration time.

\section{Femtosecond laser systems for cataract surgery}

The Catalys Precision Laser system consists of a femtosecond near infrared laser with wavelength of $1,030 \mathrm{~nm}$, pulse duration of $600 \mathrm{fs}$, pulse energy range of 3 to $10 \mu \mathrm{J}$, and pulse repetition rate of around $60 \mathrm{kHz}$. This laser is combined with a 3D spectral-domain OCT system (wavelength: $830 \mathrm{~nm}$ ) that guides laser delivery and a disposable Liquid Optics Interface that allows a gentle docking with minimal IOP rise and clear optics for excellent imaging and laser delivery. Other features of the system are: precise capsulotomies within $30 \mu \mathrm{m}$, complete segmentation and softening of the cataract with adjustable grid sizing, and multiple corneal incision centration options that are based on anatomical landmarks.

The LenSx system consists of a $50 \mathrm{kHz}$ femtosecond infrared laser that has a pulse width of 600-800 fs, a central laser wavelength of $1,030 \mathrm{~nm}$, and maximum pulse energy of $15 \mu \mathrm{J}$. This laser is combined with a $3 \mathrm{D}$ spectral-domain OCT system providing visualization of the entire anterior segment during the surgical procedure and a liquid-free curved patient interface (SoftFit). The system allows the performance of precise capsulotomies, lens fragmentation, incisions, and arcuate incisions.

\section{Statistical analysis}

Data analysis was performed using the software SPSS for Windows version 19.0 (IBM, Armonk, NY, USA). Normality of data samples was evaluated by means of the Kolmogorov-Smirnov test. When parametric analysis was possible, the Student's $t$-test for paired data was used for comparisons between preoperative and postoperative data, whereas the Wilcoxon rank-sum test was applied to assess the significance of such differences when parametric analysis was not possible. For the comparison between femtosecond laser platforms, the Student's $t$-test for unpaired data was used if parametric statistics could be applied, whereas the Mann-Whitney test was used if parametric statistics could not be applied. In addition, the chi-square test was used for comparing percentages between groups. Correlation coefficients (Pearson or Spearman depending if normality condition could be assumed) were used to assess the correlation between different variables. For all statistical tests, a $P$-value of $<0.05$ was considered as statistically significant.

\section{Results}

A total of 90 eyes from 45 patients with a mean age of 73.2 years (standard deviation: 6.7; median: 74.0, range: 61-86 years) were included in the study. This sample comprised 22 males (48.9\%) and 23 females (51.1\%). Two different doctors performed the surgeries: 46 eyes $(51.1 \%)$ by PCH Jr and 44 eyes (48.9\%) by RPR. Different models of IOL were implanted: SN60WF (29 eyes, 32.2\%), SN6AT3 (1 eye, $1.1 \%$ ), SN6AT4 (1 eye, 1.1\%), SN6AT5 (1 eye, 1.1\%), 
STAAR (15 eyes, 16.7\%), ZCB00 (33 eyes, 36.7\%), ZCT300 (4 eyes, 4.4\%), ZCT400 (1 eye, 1.1\%), and ZMB00 ( 5 eyes, $5.6 \%)$. No statistically significant differences between groups were found preoperatively at the level of nuclear sclerosis (mean \pm standard deviation, Catalys vs LenSx, 2.00 \pm 0.75 vs $2.06 \pm 0.77, P=0.74)$, cortical cataract grade $(0.90 \pm 0.96$ vs $0.82 \pm 0.90, P=0.73)$, and posterior subcapsular cataract grade $(0.52 \pm 0.95$ vs $0.38 \pm 0.75, P=0.49)$.

\section{Intraoperative outcomes}

Table 1 displays some numerical parameters recorded intraoperatively in the two groups of the analyzed sample. As shown, a significantly higher $\operatorname{CDE}(P=0.032)$, average phacoemulsification power $(P=0.043)$, and average torsional amplitude $(P<0.001)$ was found in the LenSx group compared to the Catalys group. Likewise, a significantly larger number of syringes $(P=0.003)$ to seal the corneal incision, a longer patient interface preparation time $(P<0.001)$, more severe perception of pressure by patient $(P=0.014)$, and more cases of subconjunctival hemorrhage $(P<0.001)$ were found in the LenSx group. In contrast, the suction time was significantly longer in the Catalys group $(P<0.001)$ (Table 1$)$. A complete capsulotomy was achieved in a significantly larger number of eyes in the Catalys group compared to the LenSx group $(P=0.002)$. Anterior and posterior capsular tears were not reported in any group.

Regarding corneal incisions, the primary incision was observed to be opened in $71.1 \%(32 / 45)$ and $86.7 \%(39 / 45)$ of eyes in the Catalys and LenSx groups, respectively $(P=0.071)$, whereas the secondary incision was opened in $71.1 \%(32 / 45)$ and $77.8 \%(35 / 45)$ of eyes, respectively $(P=0.468)$. Limbal relaxing incisions were found to be opened in $90.9 \%(20 / 22)$ and $76.2 \%(16 / 21)$ of eyes in the Catalys and LenSx groups, respectively $(P=0.191)$.

Table I Intraoperative parameters in the two groups of the analyzed sample

\begin{tabular}{|c|c|c|c|}
\hline Mean (SD) & Catalys & LenSx & $P$-value \\
\hline \multicolumn{4}{|l|}{ Median (range) } \\
\hline Patient interface preparation time & $2: 02(1: 28)$ & $3: 36(1: 29)$ & $<0.001$ \\
\hline (minutes:seconds) & $\mathrm{I}: 36(0: 54$ to $8: 55)$ & $3: 10$ (1:38 to $9: 27)$ & \\
\hline Suction time & $3: 55(1: 06)$ & $2: 54(0: 45)$ & $<0.001$ \\
\hline (minutes:seconds) & $3: 45$ (2:30 to $9: 23)$ & $2: 53$ (1:08 to $4: 19)$ & \\
\hline \multirow[t]{2}{*}{ Number of attempts of docking } & $1.27(0.65)$ & $1.62(1.19)$ & 0.168 \\
\hline & $1.00(1$ to 4$)$ & $\mathrm{I} .00$ (I to 5$)$ & \\
\hline Perception of pressure by patient & $1.31(1.12)$ & $2.02(\mathrm{I} .4 \mathrm{I})$ & 0.014 \\
\hline (0-none, 5-severe) & $1.00(0$ to 4$)$ & $2.00(0$ to 5$)$ & \\
\hline Loss of vision (Yes/No) & Yes $2.2 \%$ & Yes $4.4 \%$ & 0.398 \\
\hline Complete capsulotomy (Yes/No) & Yes $100.0 \%$ & Yes $80.0 \%$ & 0.002 \\
\hline \multirow[t]{2}{*}{ Number of syringes used } & $0.89(0.42)$ & $1.18(0.45)$ & 0.003 \\
\hline & $1.00(0.50$ to 2.00$)$ & $1.20(0.50$ to 2.00$)$ & \\
\hline Nucleus removal time & $2: 37(1: 32)$ & $2: 49(1: 35)$ & 0.600 \\
\hline (minutes:seconds) & $\mathrm{I}: 53$ (I:04 to 8:0I) & $2: 03$ (1:04 to $6: 55)$ & \\
\hline Cortex removal time & I:09 (0:34) & $\mathrm{I}: 09(0: 3 \mathrm{I})$ & 0.973 \\
\hline (minutes:seconds) & $\mathrm{I}: 02(0: 36$ to $\mathrm{I}: 02)$ & $0: 58(0: 26$ to $3: 00)$ & \\
\hline \multirow[t]{2}{*}{ Ultrasound time (seconds) } & I8.3I (17.44) & $23.85(18.27)$ & 0.108 \\
\hline & $18.60(0$ to 50.60$)$ & 23.50 (0 to 58.70$)$ & \\
\hline \multirow[t]{2}{*}{ Cumulative dissipated energy } & $4.60(4.77)$ & $6.92(5.78)$ & 0.032 \\
\hline & $3.75(0$ to 15.89$)$ & $5.17(0$ to 20.53$)$ & \\
\hline \multirow[t]{2}{*}{ Effective phacoemulsification time (seconds) } & $6.80(7.16)$ & $8.86(8.19)$ & 0.082 \\
\hline & 4.40 (0 to 26$)$ & $9.10(0$ to 33.80$)$ & \\
\hline \multirow[t]{2}{*}{ Average phacoemulsification power (\%) } & $22.38(18.36)$ & $30.38(15.38)$ & 0.043 \\
\hline & $22.40(0$ to 52.60$)$ & $32.70(0$ to 52.50$)$ & \\
\hline \multirow[t]{2}{*}{ Torsional time (seconds) } & $11.19(10.55)$ & $15.48(\mid 1.50)$ & 0.066 \\
\hline & $12.00(0$ to 34$)$ & 14.10 (0 to 40$)$ & \\
\hline \multirow[t]{2}{*}{ Average torsional amplitude (\%) } & $29.10(24.95)$ & $51.55(22.73)$ & $<0.001$ \\
\hline & $33.00(0$ to 78.10$)$ & 52.10 (0 to 91.50$)$ & \\
\hline Aspiration time & $3: 31(1: 16)$ & $3: 30(1: 15)$ & $0.94 I$ \\
\hline (minutes:seconds) & $3: 07(2: 02$ to $6: 3 I)$ & $3: 10(0: 22$ to $6: 57)$ & \\
\hline \multirow[t]{2}{*}{ Fluid used $(\mathrm{mL})$} & $75.98(36.5 I)$ & $79.36(33.79)$ & 0.532 \\
\hline & 56.00 (39 to 187$)$ & 69.00 (34 to 168$)$ & \\
\hline Subconjunctival hemorrhage (Yes/No) & Yes $33.3 \%$ & Yes $73.3 \%$ & $<0.001$ \\
\hline
\end{tabular}

Abbreviation: SD, standard deviation. 


\section{Clinical outcomes}

No statistically significant differences between groups in IOP $(17.1 \pm 3.9$ vs $16.2 \pm 4.7, P=0.22)$ and LogMAR uncorrected distance visual acuity $(0.26 \pm 0.24$ vs $0.27 \pm 0.24$, $P=0.71)$ were found the day after surgery. At 1 week postoperatively, LogMAR CDVA was $0.02 \pm 0.10$ and $0.01 \pm 0.06$ $(P=0.91)$ in the Catalys and LenSx groups, respectively. At 1 month after surgery, similar mean values were found in each group, with no significant differences $(0.02 \pm 0.08$ vs $0.00 \pm 0.07, P=0.48)$.

Figure 1 shows the change in endothelial cell density during follow-up in the two groups of the analyzed samples. Mean endothelial cell count was $2,494 \pm 382$ cells preoperatively, 2,270 \pm 504 cells after 1 week, and 2,240 \pm 490 after 1 month postoperatively. A statistically significant decrease in the endothelial cell density was observed at 1 week postoperatively in both groups $(P<0.001)$, with no significant changes afterwards ( 1 week to 1 month, Catalys $P=0.08$, LenSx $P=0.60$ ). Differences between groups in preoperative ( $P=0.79$ ) and postoperative cell count ( 1 week $P=0.24,1$ month $P=0.47$ ) did not reach statistical significance. Mean endothelial cell change was $179.0 \pm 247.1$ and $282.4 \pm 354.2 \mathrm{cell} / \mathrm{mm}^{2}$ $(P=0.14)$ at 1 week postoperatively, and $244.0 \pm 297.5$ and $261.5 \pm 298.2 \mathrm{cell} / \mathrm{mm}^{2}(P=0.68)$ at 1 month postoperatively in the Catalys and LenSx groups, respectively.

\section{Correlation between intraoperative data and cataract density}

No correlation was found between $\mathrm{CDE}$ and nuclear sclerosis density in the Catalys group ( $r=0.024, P=0.874$ ) (Figure 2). Likewise, a poor and not statistically significant correlation was found between these two parameters in the LenSx group ( $r=0.272, P=0.071$ ) (Figure 3). No correlation was found between EPT and nuclear sclerosis density in the Catalys group $(r=-0.118, P=0.439)$ (Figure 4$)$ and in the LenSx group $(r=0.096, P=0.530)$ (Figure 5).

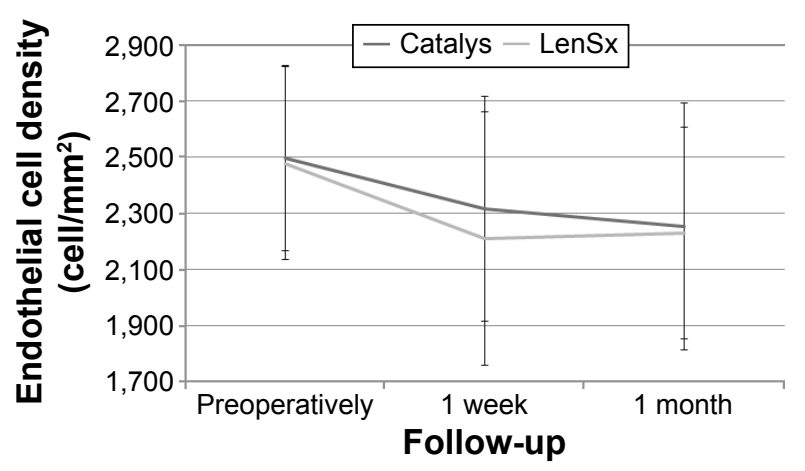

Figure I Change in endothelial cell density during the follow-up in the two groups.

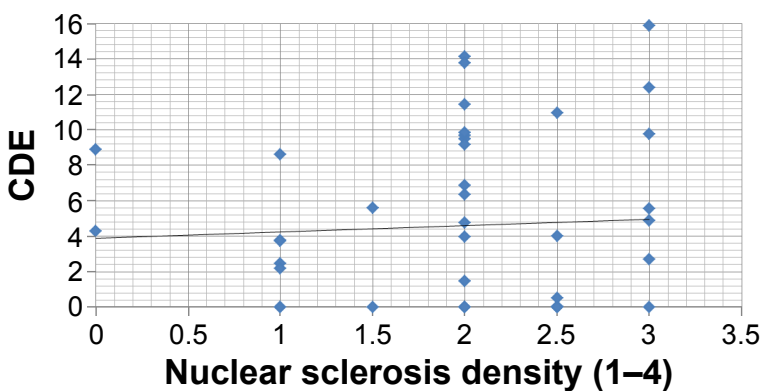

Figure 2 Scattergram showing the relationship between nuclear sclerosis density and $\mathrm{CDE}$ in the Catalys group.

Abbreviation: CDE, cumulative dissipated energy.

\section{Complications}

At 1 day after surgery, significant corneal edema (grade 1+ or more) was observed in 24 (53.3\%) and 20 eyes (44.4\%) in the Catalys and LenSx groups, respectively $(P=0.399)$. Regarding the presence of cells in the anterior chamber, it was clinically relevant (grade 1+ or more) in 20 (44.4\%) and 21 eyes (46.7\%) in the Catalys and LenSx groups, respectively $(P=0.832)$. The incidence of clinically relevant flare (grade $1+$ or more) the day after surgery was $26.7 \%$ (12 eyes) and $28.9 \%$ (13 eyes) in the Catalys and LenSx groups, respectively $(P=0.814)$.

A total of 19 eyes required zero phaco energy, 15 eyes from the Catalys group and four eyes from the LenSx group. The fellow eyes of these four eyes of the LenSx group were operated with the Catalys system using also zero phaco energy. However, the fellow eyes of the 15 Catalys zerophaco cases required some level of phaco energy when the LenSx system was used. A total of eight first eyes required zero phaco energy with the Catalys system.

\section{Comparison of intraoperative data between surgeons}

Table 2 displays a comparative analysis of the intraoperative data obtained in the two groups of the analyzed sample for

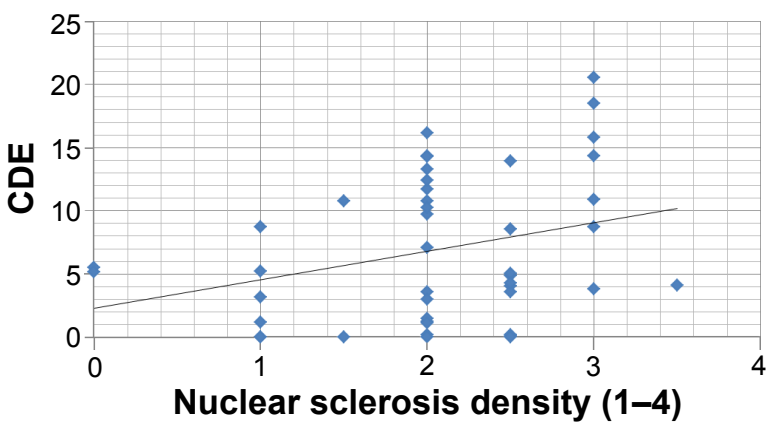

Figure 3 Scattergram showing the relationship between nuclear sclerosis density and $C D E$ in the LenSx group.

Abbreviation: $\mathrm{CDE}$, cumulative dissipated energy. 


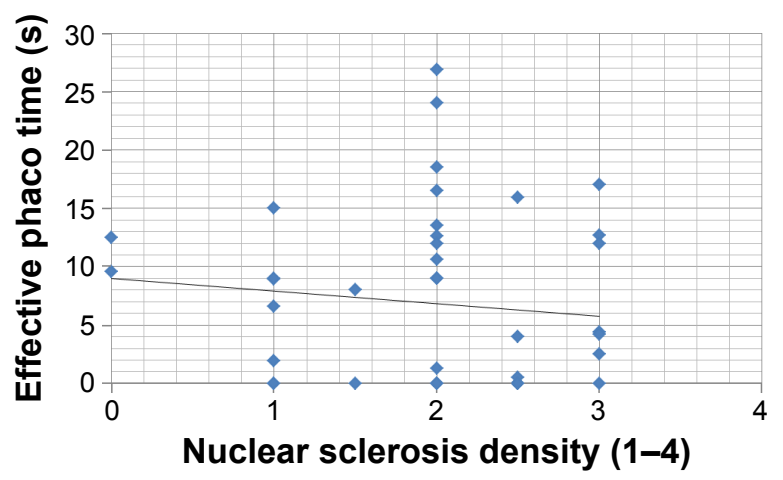

Figure 4 Scattergram showing the relationship between nuclear sclerosis density and effective phaco time in the Catalys group.

each surgeon participating in the study. As shown, there were statistically significant differences between surgeons with both laser systems in patient interface preparation $(P \leq 0.035)$, nucleus removal time $(P<0.001)$, ultrasound time $(P<0.001)$, $\mathrm{CDE}(P<0.001)$, EPT $(P<0.001)$, average phacoemulsification power $(P<0.001)$, torsional time $(P<0.001)$, average torsional amplitude $(P \leq 0.002)$, aspiration time $(P<0.001)$, and fluid used $(P<0.001)$. It should be noted that no statistically significant differences were found preoperatively in nuclear sclerosis grade $(P \geq 0.064)$ between the eyes operated on by each surgeon with each laser system. In contrast, there were statistically significant differences between surgeons in the cortical cataract grade with the Catalys ( $\mathrm{PCH} J \mathrm{~J} 0.59 \pm 0.89$ vs RPR 1.23 $\pm 0.95, P=0.019$ ) and the LenSx systems ( $\mathrm{PCH} \mathrm{Jr}$ $0.50 \pm 0.78$ vs RPR $1.16 \pm 0.90, P=0.012)$ as well as in the posterior subcapsular cataract grade with the Catalys system (PCH Jr $0.26 \pm 0.86$ vs RPR $0.80 \pm 0.98, P=0.017$ ). In addition, there were no statistically significant differences between surgeons in the clinical outcomes obtained with the two laser platforms evaluated $(P \geq 0.104)$ (Table 3).

\section{Discussion}

The current study was aimed at comparing two different femtosecond laser systems to perform cataract surgery, the

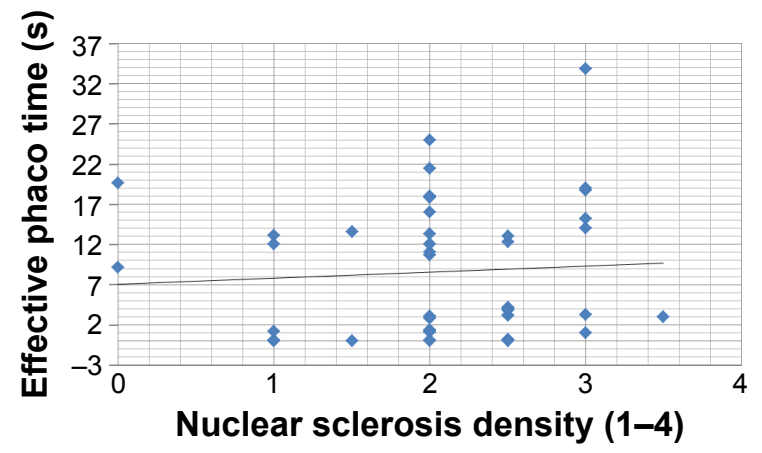

Figure 5 Scattergram showing the relationship between nuclear sclerosis density and effective phaco time in the LenSx group.
Catalys and the LenSx systems. Both systems have been demonstrated to provide excellent clinical outcomes ${ }^{6,7,9,11-13,15,16}$ and an optimized and predictable intraoperative performance, even in complex cases. ${ }^{17-20}$ However, a comparison between them has not been performed to investigate if technical differences between systems in terms of laser features and docking system have an influence on intraoperative and postoperative outcomes. For this reason, we have compared several intraoperative parameters, such as ultrasound time, EPT, CDE, number of dock attempts, as well as corneal endothelial changes and postoperative visual outcomes in two groups of eyes undergoing cataract surgery with the Catalys and LenSx femtosecond laser systems. In order to avoid the potential interference of intersubject differences in the statistical analysis of the outcomes, an intraindividual study has been conducted with random assignment of the use of one laser system in one eye and the other in the fellow eye of each subject included.

The patient interface preparation time was found to be significantly lower with the Catalys system. This is due to the fact that the Catalys interface requires no assembly, whereas the LenSx SoftFit requires assembly of the curved interface to the patient interface. It should be considered that the Catalys system has a specific disposable device for an optimized docking by filling in corneal surface irregularities with liquid, creating a wide field of view, minimizing IOP rise and minimizing the scleral contact of the interface. In contrast, the LenSx platform uses a liquid-free curved contact patient interface. The use or not of liquid in the patient interface that could theoretically neutralize corneal irregularities and facilitate the docking may be the main reason for such discrepancies between devices. Furthermore, differences in the area of scleral contact of the interface as well as higher suction pressure with the LenSx seem to be the main reason for the statistically significant difference between laser systems in the incidence of subconjunctival hemorrhage after surgery, with a lower percentage in the group of eyes undergoing surgery with the Catalys system. All these outcomes are consistent with those obtained in an experimental study by Talamo et $\mathrm{al}^{21}$ showing that a liquid interface was better than a liquid-free curved contact interface in terms of elimination of corneal folds, improved globe stability, reduced subconjunctival hemorrhage, and lower IOP rise. Likewise, Schultz et al ${ }^{22}$ demonstrated in a prospective clinical trial including 100 eyes that a minor increase in IOP is induced using a fluid-filled interface. From the perspective of the patient, this difference in the interface of the two laser systems was expressed in our series as a significant difference in the sensation of pressure, with higher scores when 
Table 2 Intraoperative parameters in the two groups of the analyzed sample stratified for the surgeon

\begin{tabular}{|c|c|c|c|c|c|c|}
\hline \multirow{2}{*}{$\begin{array}{l}\text { Mean (SD) } \\
\text { Median (range) } \\
\text { Surgeon }\end{array}$} & \multicolumn{3}{|l|}{ Catalys } & \multicolumn{3}{|l|}{ LenSx } \\
\hline & $\mathrm{PCH} \mathrm{Jr}$ & RPR & $P$-value & $\mathrm{PCH} \mathrm{Jr}$ & RPR & $P$-value \\
\hline Patient interface preparation & $2: 30(1: 52)$ & $\mathrm{I}: 32(0: 37)$ & 0.027 & $4: 03(I: 4 I)$ & $3: 08(1: 04)$ & 0.035 \\
\hline time (minutes:seconds) & $\mathrm{I}: 49(\mathrm{I}: 13$ to $8: 55)$ & $\mathrm{I}: 2 \mathrm{I}(0: 54$ to $3: 4 \mathrm{I})$ & & $3: 40(2: 24$ to $9: 27)$ & $2: 52(1: 38$ to $6: 23)$ & \\
\hline Suction time & $3: 46(0: 50)$ & $4: 06(1: 19)$ & 0.315 & $2: 28(0: 39)$ & $3: 21(0: 34)$ & $<0.001$ \\
\hline (minutes:seconds) & $3: 35(2: 30$ to $6: 39)$ & $3: 46(4: 12$ to $11: 05)$ & & $2: 28(1: 08$ to $3: 37)$ & $3: 23(2: 20$ to $4: 19)$ & \\
\hline \multirow[t]{2}{*}{ Number of attempts of docking } & $\mathrm{I} .48(0.85)$ & $\mathrm{I} .05(0.2 \mathrm{I})$ & 0.022 & $1.41(0.91)$ & $1.86(1.42)$ & 0.227 \\
\hline & $1.00(\mathrm{I}$ to 4$)$ & $1.00(\mathrm{I}$ to 2$)$ & & $1.00(1$ to 4$)$ & $1.00(1$ to 5$)$ & \\
\hline Perception of pressure by & $1.65(1.15)$ & $0.95(1.00)$ & 0.038 & $2.23(1.34)$ & $1.77(1.48)$ & 0.219 \\
\hline patient (0-none, 5 -severe) & $1.00(0$ to 4$)$ & $1.00(0$ to 3$)$ & & $2.00(0$ to 4$)$ & $2.00(0$ to 5$)$ & \\
\hline Loss of vision (Yes/No) & Yes $0.00 \%$ & Yes $9.1 \%$ & 0.139 & Yes $4.3 \%$ & Yes $13.6 \%$ & 0.274 \\
\hline Complete capsulotomy (Yes/No) & Yes $100.0 \%$ & Yes $100.0 \%$ & 1.00 & Yes $78.3 \%$ & Yes $81.8 \%$ & 0.766 \\
\hline \multirow[t]{2}{*}{ Number of syringes used } & $0.86(0.42)$ & $0.91(0.43)$ & 0.725 & $1.10(0.49)$ & $1.27(0.40)$ & 0.202 \\
\hline & $0.75(0.50$ to 2.00$)$ & $1.00(0.50$ to 1.50$)$ & & $1.00(0.50$ to 2.00$)$ & $1.50(0.50$ to 2.00$)$ & \\
\hline Nucleus removal time & $\mathrm{I}: 33(0: 17)$ & $3: 41(1: 33)$ & $<0.001$ & $\mathrm{I}: 29(0: 18)$ & $3: 55(1: 20)$ & $<0.001$ \\
\hline (minutes:seconds) & $1: 32(1: 04$ to $1: 56)$ & $3: 29(1: 16$ to $8: 01)$ & & $1: 26(1: 04$ to $2: 00)$ & $3: 56(1: 08$ to $6: 55)$ & \\
\hline Cortex removal time & $0: 59(0: 18)$ & $1: 19(0: 44)$ & $<0.001$ & $\mathrm{I}: 00(0: 17)$ & I:17 (0.39) & 0.069 \\
\hline (minutes:seconds) & $0: 54(0: 36$ to $1: 43)$ & $1: 06(0: 36$ to $3: 43)$ & & $0: 56(0: 40$ to $1: 59)$ & I:II (0:26 to $3: 00)$ & \\
\hline \multirow[t]{2}{*}{ Ultrasound time (seconds) } & $33.04(10.6)$ & $2.91(5.84)$ & $<0.001$ & $38.24(10.98)$ & $8.80(10.43)$ & $<0.001$ \\
\hline & $32.30(18.00$ to 50.60$)$ & $0.00(0.00$ to 18.60$)$ & & $35.90(21.20$ to 58.70$)$ & $4.75(0.00$ to 43.50$)$ & \\
\hline \multirow[t]{2}{*}{ Cumulative dissipated energy } & $8.25(3.8 I)$ & $0.79(1.62)$ & $<0.001$ & II.II (4.4I) & $2.55(3.23)$ & $<0.001$ \\
\hline & 8.88 (2.46 to 15.89$)$ & $0.00(0.00$ to 5.57$)$ & & $10.76(3.15$ to 20.53$)$ & $1.35(0.00$ to 14.35$)$ & \\
\hline Effective phacoemulsification & $12.67(5.23)$ & $0.67(1.36)$ & $<0.001$ & $15.72(5.58)$ & $1.68(1.56)$ & $<0.001$ \\
\hline time (seconds) & $12.00(4$ to 26$)$ & $0.00(0.00$ to 4.40$)$ & & $13.60(9.10$ to 33.80$)$ & $1.20(0.00$ to 4.20$)$ & \\
\hline Average phacoemulsification & $36.87(10.22)$ & $7.22(11.23)$ & $<0.001$ & $42.54(6.19)$ & $17.66(11.14)$ & $<0.001$ \\
\hline power (\%) & $39.30(13.50$ to 52.60$)$ & $0.00(0.00$ to 32.80$)$ & & 43.20 (27.40 to 52.50$)$ & $20.00(0.00$ to 40.40$)$ & \\
\hline \multirow[t]{2}{*}{ Torsional time (seconds) } & $19.76(6.81)$ & $2.24(4.48)$ & $<0.001$ & $23.61(7.88)$ & $6.97(7.98)$ & $<0.001$ \\
\hline & $19.60(8.00$ to 34.00$)$ & $0.00(0.00$ to 14.20$)$ & & $22.30(12.10$ to 40.00$)$ & $4.15(0.00$ to 33.70$)$ & \\
\hline \multirow[t]{2}{*}{ Average torsional amplitude (\%) } & $40.48(7.12)$ & $17.20(31.00)$ & 0.001 & $47.50(7.24)$ & $55.78(31.48)$ & 0.002 \\
\hline & $41.60(22.90$ to 51.70$)$ & $0.00(0.00$ to 78.10$)$ & & $47.40(33.60$ to 60.90$)$ & 69.15 (0.00 to 91.50$)$ & \\
\hline Aspiration time & $2: 44(0: 25)$ & $4: 2 I(I: 20)$ & $<0.001$ & $2: 48(0: 28)$ & $4: 15(1: 23)$ & $<0.001$ \\
\hline (minutes:seconds) & $2: 47(2: 02$ to $3: 31)$ & $4: 14(2: 16$ to $6: 31)$ & & $2: 40(1: 47$ to $3: 56)$ & $4: 20(0: 22$ to $6: 57)$ & \\
\hline \multirow[t]{2}{*}{ Fluid used (mL) } & $51.26(6.50)$ & $101.82(37.15)$ & $<0.001$ & $53.13(10.03)$ & $106.77(27.33)$ & $<0.001$ \\
\hline & 53.00 (39 to 64$)$ & 96.50 (50 to 187$)$ & & 52.00 (34 to 72$)$ & $107.50(65$ to 168$)$ & \\
\hline $\begin{array}{l}\text { Subconjunctival hemorrhage } \\
(\mathrm{Yes} / \mathrm{No})\end{array}$ & Yes $30.4 \%$ & Yes $36.4 \%$ & 0.673 & Yes $51.6 \%$ & Yes $48.4 \%$ & 0.920 \\
\hline
\end{tabular}

Abbreviations: $\mathrm{PCH}$ Jr/RPR, surgeons; SD, standard deviation.

Table 3 Summary of the postoperative outcomes obtained in the two groups stratified for the surgeon

\begin{tabular}{|c|c|c|c|c|c|c|}
\hline \multirow{2}{*}{$\begin{array}{l}\text { Mean (SD) } \\
\text { Median (range) } \\
\text { Surgeon }\end{array}$} & \multicolumn{3}{|l|}{ Catalys } & \multicolumn{3}{|l|}{ LenSx } \\
\hline & PCH Jr & RPR & $P$-value & PCH Jr & RPR & $P$-value \\
\hline \multirow[t]{2}{*}{ I Week LogMAR CDVA } & $0.01(0.08)$ & $0.02(0.11)$ & 0.923 & $0.02(0.07)$ & $0.00(0.05)$ & 0.495 \\
\hline & $0.00(-0.12$ to 0.30$)$ & $0.00(-0.12$ to 0.40$)$ & & 0.00 (0.00 to 0.30$)$ & $0.00(-0.12$ to 0.10$)$ & \\
\hline I Week endothelial cell & $2,236.6(434.8)$ & $2,394.4(352.9)$ & 0.193 & $2,200.6(455.0)$ & $2,215.3(456.1)$ & 0.914 \\
\hline count (cell/mm²) & $2,183.5(1,242$ to 2,993$)$ & $2,426.0$ (I,727 to 2,911$)$ & & $2,282.0(1,234$ to 3,062$)$ & $2,253.5$ (962 to 2,911$)$ & \\
\hline I Week cell density & $206.7(276.8)$ & $15 \mid .3(2 \mid 6.3)$ & 0.622 & $224.2(313.1)$ & $343.4(390.6)$ & 0.261 \\
\hline change (cell/mm²) & $127.5(-207$ to $76 \mid)$ & $81.0(-148$ to 607$)$ & & $|3| .0(-388$ to 835$)$ & $2,28.0(-297$ to $I, 174)$ & \\
\hline \multirow[t]{2}{*}{ I Month LogMAR CDVA } & $0.01(0.06)$ & $0.02(0.10)$ & 0.574 & $0.01(0.08)$ & $-0.01(0.04)$ & 0.313 \\
\hline & $0.00(-0.12$ to 0.18$)$ & $0.00(-0.12$ to 0.40$)$ & & $0.00(-0.12$ to 0.30$)$ & $0.00(-0.12$ to 0.10$)$ & \\
\hline I Month endothelial cell & $2,147.4(443.5)$ & $2,36 \mid .3(4 \mid 8.5)$ & 0.104 & $2,202.1(342.6)$ & $2,256.5(4 \mid 2.4)$ & 0.632 \\
\hline count (cell/mm²) & $2,033.0(1,526$ to 3,099$)$ & $2,397.5$ (I,323 to 3,217$)$ & & $2,243.0(1,527$ to 3,060$)$ & $2,280.5(1,497$ to 2,942$)$ & \\
\hline I Month cell density & $300.9(291.8)$ & I84.5 (298.2) & 0.184 & $222.6(278.1)$ & $302.2(319.2)$ & 0.376 \\
\hline change (cell/mm²) & $219.0(-105$ to 834$)$ & $128.5(-225$ to 1,011$)$ & & I84.0 (-246 to $87 \mid)$ & $298.0(-301$ to $I, 008)$ & \\
\hline
\end{tabular}

Abbreviations: CDVA, corrected distance visual acuity; PCH Jr/RPR, surgeons; SD, standard deviation. 
the laser with the liquid-free curved interface was used in spite of the significantly lower suction time associated. This confirms that the suction time was not a factor contributing to this higher sensation of pressure described by patients when the LenSx system was used.

Concerning the nucleus removal time, cortex removal time, ultrasound time, EPT, torsional time, aspiration time, and fluid used, no statistically significant differences were found between groups, revealing that a similar surgical performance was achieved in these terms with the two laser systems evaluated. EPT values observed in the current series were of the same magnitude reported by other authors evaluating the same or other femtosecond laser platforms, and lower than those reported for conventional phacoemulsification surgery..$^{8,11-13,15}$ In contrast to all these parameters, significant differences between groups were found in CDE, average phacoemulsification power and average torsional amplitude, with the highest values for the LenSx system. Some technical aspects of the femtosecond laser systems may be related to these findings, such as differences between laser platforms in grid sizing, pulse duration and energy, or repetition rate. Conrad-Hengerer et $\mathrm{al}^{23}$ found that with the same laser system (Catalys), a statistically significant lower EPT could be obtained by changing the grid size.

$\mathrm{CDE}$ and average phacoemulsification power values observed in the current series for the two laser system groups were lower than those with conventional phacoemulsification surgery, ${ }^{8}$ confirming the benefit of femtosecond laser technology in terms of reduction of phaco energy. Indeed, poor or no correlation was found in both groups between nuclear sclerosis density and CDE or EPT. It should be noted that anterior segment inflammation has been confirmed to be less after femtosecond laser-assisted cataract surgery than after manual cataract surgery, mainly due to the reduction in phacoemulsification energy. ${ }^{24}$

In our series, no anterior or posterior capsule tearing was observed, which was coherent with the high level of experience in femtosecond laser-assisted cataract surgery of surgeons participating in the study. Bali et $\mathrm{al}^{25}$ confirmed that surgeons with prior experience with femtosecond lasers had fewer complications in the first 100 cases, and Nagy et $\mathrm{al}^{26}$ confirmed in a retrospective study that relevant complications of femtosecond laser-assisted cataract surgery occurred during the first 100 cases. Regarding capsulotomy, it was completed with the laser procedure in a large number of cases, although a significantly larger percentage of complete capsulotomies was found in the Catalys group (100\% vs $80 \%$ ). Several factors may have accounted for this finding, such as differences in the pulse energy. Mastropasqua et $\mathrm{al}^{27}$ found in a prospective nonrandomized single-blinded study that the degree of irregularity in capsulorhexis was higher at increasing energy settings. More studies on this issue are still required to extract more consistent conclusions. The performance of corneal incisions was also found to be excellent with both laser systems, with no statistically significant differences between them. This was consistent with previous evidences reported in experimental and clinical studies evaluating the corneal incision performance of different femtosecond laser platforms for cataract surgery. ${ }^{9,10}$

Besides the analysis of the intraoperative performance with both laser systems, postoperative clinical outcomes were analyzed in each group and compared. No statistically significant differences in LogMAR CDVA between groups were observed, revealing that both laser systems generate precise capsulotomies, promoting IOL stability and centration. Miháltz et $\mathrm{al}^{6}$ demonstrated that capsulotomy performed with femtosecond laser technology induced significantly less internal aberrations compared to eyes that underwent conventional capsulorhexis. Finally, no significant differences in corneal endothelial changes were observed between groups. This confirms the safety of both femtosecond laser systems in terms of preservation of the integrity of the corneal endothelium after surgery. This is consistent with previous scientific evidence on this issue that there was a lower rate of endothelial cell loss with femtosecond laser systems compared to conventional phacoemulsification, mainly due to the reduction in EPT and phaco energy. ${ }^{12,16,28}$ Likewise, in agreement with the reduced levels of phaco energy required with both femtosecond laser platforms, no statistically significant differences were found between groups in the incidence of early postoperative corneal edema or flare.

One potential drawback of the current study is the inclusion of the data of two different experienced surgeons who used different phaco techniques that may introduce variability. PCH Jr employs a divide and conquer technique with phaco pulses to clear the phaco tip, resulting in more phaco use, but quicker removal times, and less fluidics (Table 2). RPR uses a phaco flip technique utilizing high vacuum and fluidics and relatively low to no phaco time, but longer removal times (Table 2). The potential contribution of this factor to the final outcome has been analyzed by evaluating the differences among surgeons in intraoperative and clinical outcomes. Significant differences were found between surgeons in both groups for several parameters, such as patient interface preparation, nucleus removal time, ultrasound time, CDE, EPT, or average phacoemulsification power. Several factors may 
have accounted for this discrepancy, but the different surgical protocol followed by each doctor seems to be the main reason for that. Likewise, the significant differences in preoperative cortical and subcapsular cataract grades between the groups of eyes operated by each surgeon may have also contributed to this intraoperative discrepancy. In any case, the same significant differences between doctors were identified in both groups and each doctor performed the same number of cataract surgical procedures with each laser platform. Therefore, the surgeon factor contributed in the same manner, not biasing the outcome of one system over the other. Furthermore, no significant differences in postoperative clinical outcomes were found in the groups of eyes operated by each surgeon.

In conclusion, the Catalys and LenSx femtosecond laser platforms allow surgeons to perform cataract surgery safely, with reduced EPT, CDE, and phacoemulsification power. This leads to a reduced number of postoperative complications, with preservation of corneal endothelium integrity. Significant differences between these two laser systems are present in the performance of capsulotomy and the procedure of docking. Specifically, the Catalys system has an optimized patient interface, reducing the time to initiate docking, minimizing the sensation of pressure perceived by the patient during this procedure and reducing the incidence of subconjunctival hemorrhage. Catalys showed superiority in complete capsulotomy in comparison to LenSx. Future studies should confirm if the small in magnitude but statistically significant differences found in our series in CDE and phacoemulsification power between the laser systems may have a potential effect on other parameters not evaluated in the current study. In our study, differences between groups in visual acuity, corneal endothelium and early postoperative edema and flare did not reach statistical significance.

Finally, this series yielded results with what was at the time the most current software and hardware features of each platform. As these and other platforms continue to evolve and maximize various aspects of energy parameters, both in terms of software and hardware enhancements, we would both expect and welcome continued advancements to make phacoemulsification procedures safer and more efficacious in treating our patients with cataract.

\section{Disclosure}

RPR and PCH Jr was a consultant to Abbott Medical Optics. The remaining authors have no proprietary or commercial interest in the medical devices that are involved in this manuscript. The authors report no other conflicts of interest in this work.

\section{References}

1. Alió J, Rodríguez-Prats JL, Galal A, Ramzy M. Outcomes of microincision cataract surgery versus coaxial phacoemulsification. Ophthalmology. 2005;112(11):1997-2003.

2. Buckhurst PJ, Wolffsohn JS, Davies LN, Naroo SA. Surgical correction of astigmatism during cataract surgery. Clin Exp Optom. 2010;93(6): 409-418.

3. Naranjo-Tackman R. How a femtosecond laser increases safety and precision in cataract surgery? Curr Opin Ophthalmol. 2011;22(1):53-57.

4. He L, Sheehy K, Culbertson W. Femtosecond laser-assisted cataract surgery. Curr Opin Ophthalmol. 2011;22(1):43-52.

5. Palanker DV, Blumenkranz MS, Andersen D, et al. Femtosecond laserassisted cataract surgery with integrated optical coherence tomography. Sci Transl Med. 2010;2(58):58ra85.

6. Miháltz K, Knorz MC, Alió JL, et al. Internal aberrations and optical quality after femtosecond laser anterior capsulotomy in cataract surgery. $J$ Refract Surg. 2011;27(10):711-716.

7. Friedman NJ, Palanker DV, Schuele G, et al. Femtosecond laser capsulotomy. J Cataract Refract Surg. 2011;37(7):1189-1198.

8. Reddy KP, Kandulla J, Auffarth GU. Effectiveness and safety of femtosecond laser-assisted lens fragmentation and anterior capsulotomy versus the manual technique in cataract surgery. J Cataract Refract Surg. 2013;39(9):1297-1306.

9. Nagy ZZ, Filkorn T, Takács AI, et al. Anterior segment OCT imaging after femtosecond laser cataract surgery. J Refract Surg. 2013;29(2): 110-112.

10. Schultz T, Tischoff I, Ezeanosike E, Dick HB. Histological sections of corneal incisions in OCT-guided femtosecond laser cataract surgery. J Refract Surg. 2013;29(12):863-864.

11. Abell RG, Kerr NM, Vote BJ. Toward zero effective phacoemulsification time using femtosecond laser pretreatment. Ophthalmology. 2013; 120(5):942-948.

12. Abell RG, Kerr NM, Vote BJ. Femtosecond laser-assisted cataract surgery compared with conventional cataract surgery. Clin Experiment Ophthalmol. 2013;41(5):455-462.

13. Conrad-Hengerer I, Hengerer FH, Schultz T, Dick HB. Effect of femtosecond laser fragmentation on effective phacoemulsification time in cataract surgery. J Refract Surg. 2012;28(12):879-883.

14. Roberts TV, Lawless M, Chan CC, et al. Femtosecond laser cataract surgery: technology and clinical practice. Clin Experiment Ophthalmol. 2013;41(2):180-186.

15. Lauschke JL, Amjadi S, Lau OC, et al. Comparison of macular morphology between femtosecond laser-assisted and traditional cataract surgery. J Cataract Refract Surg. 2013;39(4):656-657.

16. Conrad-Hengerer I, Al Juburi M, Schultz T, Hengerer FH, Dick HB. Corneal endothelial cell loss and corneal thickness in conventional compared with femtosecond laser-assisted cataract surgery: three-month follow-up. J Cataract Refract Surg. 2013;39(9):1307-1313.

17. Szepessy Z, Takács A, Kránitz K, Filkorn T, Nagy ZZ. Intraocular femtosecond laser use in traumatic cataract. Eur J Ophthalmol. 2014; 24(4):623-625.

18. Burkhard Dick H, Schultz T. Laser-assisted cataract surgery in small pupils using mechanical dilation devices. J Refract Surg. 2013;29(12): 858-862.

19. Schultz T, Ezeanosike E, Dick HB. Femtosecond laser-assisted cataract surgery in pediatric Marfan syndrome. J Refract Surg. 2013;29(12): 650-652.

20. Kránitz K, Takács AI, Gyenes A, et al. Femtosecond laser-assisted cataract surgery in management of phacomorphic glaucoma. J Refract Surg. 2013;29(9):645-648.

21. Talamo JH, Gooding P, Angeley D, et al. Optical patient interface in femtosecond laser-assisted cataract surgery: contact corneal applanation versus liquid immersion. J Cataract Refract Surg. 2013;39(4):501-510.

22. Schultz T, Conrad-Hengerer I, Hengerer FH, Dick HB. Intraocular pressure variation during femtosecond laser-assisted cataract surgery using a fluid-filled interface. J Cataract Refract Surg. 2013;39(1):22-27. 
23. Conrad-Hengerer I, Hengerer FH, Schultz T, Dick HB. Effect of femtosecond laser fragmentation of the nucleus with different softening grid sizes on effective phaco time in cataract surgery. J Cataract Refract Surg. 2012;38(11):1888-1894.

24. Abell RG, Allen PL, Vote BJ. Anterior chamber flare after femtosecond laser-assisted cataract surgery. J Cataract Refract Surg. 2013;39(9): 1321-1326.

25. Bali SJ, Hodge C, Lawless M, Roberts TV, Sutton G. Early experience with the femtosecond laser for cataract surgery. Ophthalmology. 2012; 119(5):891-899.

26. Nagy ZZ, Takacs AI, Filkorn T, et al. Complications of femtosecond laser-assisted cataract surgery. J Cataract Refract Surg. 2014;40(1): $20-28$.
27. Mastropasqua L, Toto L, Calienno R, et al. Scanning electron microscopy evaluation of capsulorhexis in femtosecond laser-assisted cataract surgery. J Cataract Refract Surg. 2013;39(10):1581-1586.

28. Takács AI, Kovács I, Miháltz K, Filkorn T, Knorz MC, Nagy ZZ. Central corneal volume and endothelial cell count following femtosecond laser-assisted refractive cataract surgery compared to conventional phacoemulsification. J Refract Surg. 2012;28(6):387-391.
Clinical Ophthalmology

\section{Publish your work in this journal}

Clinical Ophthalmology is an international, peer-reviewed journal covering all subspecialties within ophthalmology. Key topics include: Optometry; Visual science; Pharmacology and drug therapy in eye diseases; Basic Sciences; Primary and Secondary eye care; Patient Safety and Quality of Care Improvements. This journal is indexed on

\section{Dovepress}

PubMed Central and CAS, and is the official journal of The Society of Clinical Ophthalmology (SCO). The manuscript management system is completely online and includes a very quick and fair peer-review system, which is all easy to use. Visit http://www.dovepress.com/ testimonials.php to read real quotes from published authors. 